
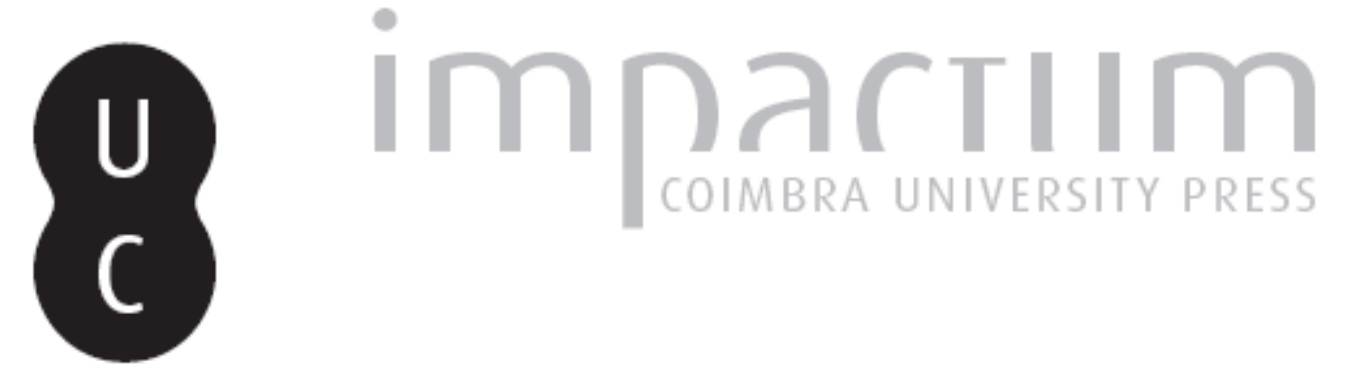

\begin{abstract}
Antecedentes sobre los impactos ecologicos de los fuegos y de otros factores antropicos en los bosques de Jubaea chilensis (Moll) Baillon: caso de estudio: microcuencas perurbanas de las ciudades de Valparaíso y Viña del Mar, Chile
\end{abstract}

Autor(es): $\quad$ Quintanilla Pérez, Víctor; Morales Constanzo, Mauricio

Publicado por: Imprensa da Universidade de Coimbra

URL

persistente:

URl:http://hdl.handle.net/10316.2/43273

DOI:

DOI:https://doi.org/10.14195/1647-7723_25-1_6

Accessed : $\quad$ 26-Apr-2023 07:34:35

A navegação consulta e descarregamento dos títulos inseridos nas Bibliotecas Digitais UC Digitalis, UC Pombalina e UC Impactum, pressupõem a aceitação plena e sem reservas dos Termos e Condições de Uso destas Bibliotecas Digitais, disponíveis em https://digitalis.uc.pt/pt-pt/termos.

Conforme exposto nos referidos Termos e Condições de Uso, o descarregamento de títulos de acesso restrito requer uma licença válida de autorização devendo o utilizador aceder ao(s) documento(s) a partir de um endereço de IP da instituição detentora da supramencionada licença.

Ao utilizador é apenas permitido o descarregamento para uso pessoal, pelo que o emprego do(s) título(s) descarregado(s) para outro fim, designadamente comercial, carece de autorização do respetivo autor ou editor da obra.

Na medida em que todas as obras da UC Digitalis se encontram protegidas pelo Código do Direito de Autor e Direitos Conexos e demais legislação aplicável, toda a cópia, parcial ou total, deste documento, nos casos em que é legalmente admitida, deverá conter ou fazer-se acompanhar por este aviso.

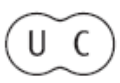


territorium/25w|.

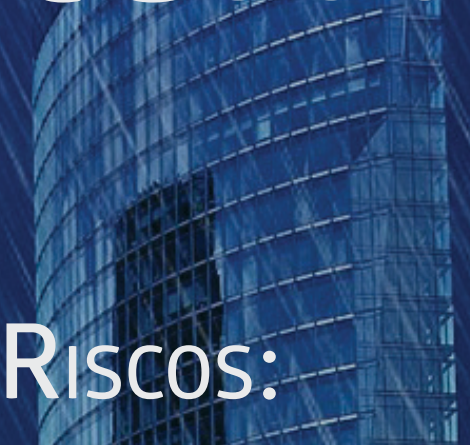

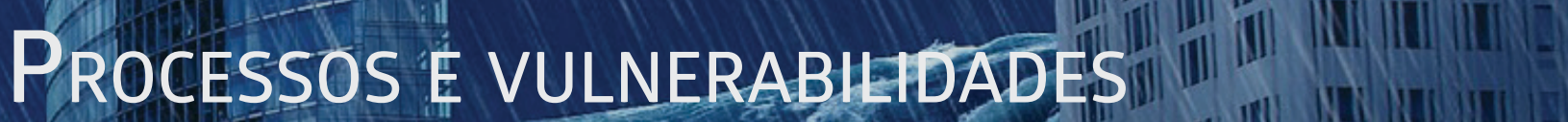

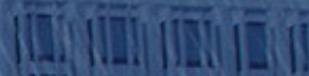
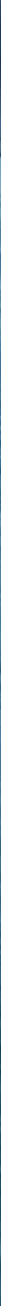

Imprensa da Universidade de Coimbra

Associação Portuguesa de Riscos, Prevenção e Segurança

2018 


\title{
ANTECEDENTES SOBRE LOS IMPACTOS ECOLOGICOS DE LOS FUEGOS Y DE OTROS FACTORES ANTROPICOS EN LOS BOSQUES DE JUBAEA CHILENSIS (MOLL) BAILLON. CASO DE ESTUDIO: MICROCUENCAS PERURBANAS DE LAS CIUDADES DE VALPARAÍSO Y VIÑA DEL MAR, CHILE*
}

\author{
ECOLOGICAL IMPACT OF WILDFIRES AND ANTHROPOGENIC ACTIVITY ON THE JUBAEA CHILENSIS (MOL) BAILLON \\ FOREST.CASE STUDY: PERI-URBAN MICRO-BASINS OF VALAPRAÍSO AND VIÑA DEL MAR CITIES, CHILE
}

Víctor Quintanilla Pérez

Universidad de Santiago de Chile (Chile) victor.quintanilla@usach.cl

Mauricio Morales Constanzo

Universidad de Santiago de Chile (Chile) m.morales.constanzo@gmail.com

\begin{abstract}
RESUMEN
Los incendios forestales que se producen anualmente durante los veranos en Chile mediterráneo, han afectado también la biodiversidad de las formaciones vegetales. Actualmente se distingue un paisaje fragmentado, sobre todo por los cambios de uso del suelo y que han reducido bastante el hábitat de la palma nativa.

El clima mediterráneo de Chile se caracteriza en los valles y cordilleras costeras por un largo y seco verano, precipitaciones nulas y constantes vientos cálidos en el litoral. Esto favorece la recurrencia y extensión de los fuegos forestales. Se expone el estado actual de la situación con respecto al bosque de la palma endémica de Chile (Jubaea chilensis (Moll) Baillon que vive asociada al matorral esclerófilo mediterráneo en el litoral de Valparaíso $\left(33^{\circ} 03^{\prime}\right.$ Sur- $71^{\circ} 3^{\prime \prime}$ Weste) y cuyo cortejo florístico, está muy alterado por los impactos de los recurrentes fuegos estivales y la acción antrópica en microcuencas costeras. Por otra parte la regeneración de los palmares es escasa debido a la explotación que realizan los lugareños de sus frutos ("coquitos") comestibles y también por la herbivoría de fauna y animales domésticos.

La especie está declarada en estado de vulnerable y el estado junto a algunas fundaciones privadas, llevan a cabo desde más o menos unos 15 años, planes de regeneración y recuperación de esta palma que es la más longeva y una de las más australes del mundo.
\end{abstract}

Palabras clave: Palmas, bosque esclerófilo, endémico, erosión de suelos.

\section{ABSTRACT}

The forest fires that occur every year in Mediterranean Chile have also affected the biodiversity of plant formations. At present a fragmented scenery is seen, mostly due to the changes in soil use, which have significantly reduced the habitat of the native palm trees.

Chile's Mediterranean climate is characterized in the coastal valleys and mountain ranges by a long and dry summer, zero precipitation, and constant warm winds on the coastline. This favours the recurrence and spread of forest fires. The current state of the situation is presented with respect to the forest of the endemic Chilean palm (Jubaea chilensis (Moll) Baillon, which lives in association with the Mediterranean sclerophyllous brush along the shores of Valparaiso ( $33^{\circ} 03^{\prime}$ South-71 ${ }^{\circ} 3^{\prime}$ West), whose floristic entourage is highly altered by the recurring impact of the summer fires and by anthropic action in coastal microbasins. On the other hand, the regeneration of palm groves is poor due to the exploitation carried out by the local people of their edible fruits (tiny coconuts) as well as by the herbivorous fauna and domestic animals. The species has been declared in a vulnerable category, and for some 15 years the State, together with some private foundations, has been carrying out regeneration and recovery plans of this palm tree, which is the longest living and one of the southernmost in the world.

Keywords: Palms, sclerophyllous forest, endemic, soil erosion.

* O texto deste artigo foi submetido em 22-11-2016, sujeito a revisão por pares a 20-04-2017 e aceite para publicação em 22-06-2017.

Este artigo é parte integrante da Revista Territorium, n. ${ }^{\circ} 25$ (I), 2018, ${ }^{\circ}$ RIscos, ISSN: 0872-8941. 


\section{Introducción}

Jubaea chilensis Mol (Baillon) endémica de Chile, es una de las palmas más longevas del globo, pudiendo superar los 700 años de vida (J. Grau, 2004). Según algunos registros palinológicos, la permanencia de esta especie en Chile data desde el Terciario, lo que puede hacer creer que la palma podría ser una especie relicta de formaciones vegetales de origen tropical (C. Villagrán y J. Armesto, 1980; A. Moreira, 2011). En la actualidad se distribuye en la zona mediterránea de Chile, en poblaciones fragmentadas aproximadamente desde los $31^{\circ} 15^{\prime}$ hasta los $35^{\circ} 30^{\prime}$ latitud sur.

La palma chilena es una de las especies de mayor valor científico de la flora de Chile, siendo el segundo representante más austral de la familia Arecaceae (Palmaceae), después de Rhopalostylis sapida, endémica de Nueva Zelanda; estas agrupaciones están consideradas entre los 68 sitios prioritarios de conservación en el país (I. Benoit, 1989).

Esta especie se caracteriza por su lento crecimiento, y por su morfología de tronco grueso más bien liso de un aspecto de estilo dórico, pues tiende a estrecharse en su base, siendo más notorio aún hacia el extremo superior, careciendo del capitel de ramas romas, que es típico en la mayoría de las palmas. El esfuerzo que la planta realiza para producir sus frutos es lo que marca el tan notorio estrechamiento del tronco, alcanzando hasta 30 metros de altura con un diámetro aproximado de 1 metro, y con ramas de más de 1 metro de longitud (Grau, 2004). Las palmas cuya corteza es de fibra, en términos estrictos no son árboles propiamente tales, sino más bien plantas de tipo herbáceas que evolucionaron a tamaños descomunales.

En un contexto histórico, la presencia de esta especie hace siglos atrás, se contaba por cientos de miles en territorio chileno. De acuerdo a ello y como antecedente, el jesuita Alonso Ovalle en el siglo XVII la describió extensamente, al igual que Darwin en 1834, cuando en su tercera visita a Chile ascendió al macizo de la Campana (región de Valparaíso), que aparte de sus observaciones científicas, demostró su admiración por los hermosos bosques de palmas y de agrupaciones esclerófilas en laderas del macizo. Sin embargo, también constató la explotación de la palma en el medio rural para la elaboración de miel, que se realiza a partir de la extracción de su savia. Cabe señalar que este tipo extracción se efectúa desde hace unos 200 años (L. González et al., 2009).

En la actualidad se han mantenido diversos procesos de degradación en los bosques mediterráneos, que han significado un retroceso gradual de las agrupaciones de palma; impactos que están asociados fundamentalmente a incendios forestales y al crecimiento y expansión de las grandes ciudades. Esta situación ha incrementado necesariamente la presión sobre los recursos naturales de la región mediterránea, que por lo demás es donde históricamente se ha concentrado la población en Chile.

En Chile se originan en promedio 6.700 incendios forestales al año (a excepción del año 2017 que se quemaron más de 364.000 hectáreas), los que han afectado una superficie promedio a de 78.500 hectáreas aproximadamente, de las cuales corresponderían en más de un $70 \%$ a formaciones boscosas nativas (I. Fernández et al., 2010; M. Castillo et al., 2013; CONAF, 2016). Sobre la distribución en el país de estos incendios, estarían concentrados principalmente en Chile central (zona mediterránea), representando sobre el $74 \%$ del total nacional de incendios, y otra parte importante, desde hace más de 15 años, en la zona templada del país (V. Quintanilla, 2002).

Entre las causas principales de los fuegos en Chile central, serían prácticamente en un $99 \%$ de origen antrópico, los cuales se suman a otros factores como la marcada estacionalidad propia de los climas mediterráneos, con veranos muy secos y cálidos, y de intensa circulación atmosférica, otorgando las condiciones necesarias para el inicio y propagación de los fuegos (V. Quintanilla y R. Castro, 1998).

La región de Valparaíso es precisamente una de las regiones administrativas con mayores registros de incendios a nivel nacional, eventos que se han constituido, desde mediados del siglo pasado, en un importante factor de degradación para las agrupaciones de palma chilena y de los ecosistemas boscosos en general; implicando una modificación de la estructura y composición de especies, dinámica sucesional, y perturbación de las interacciones ecológicas del sistema (I. Fernández et al., 2010).

El objetivo de este estudio es presentar algunos antecedentes respecto de lo que ha sucedido con la palma nativa chilena (Jubaea chilensis) frente a la larga ocurrencia de incendios forestales acaecidos en las microcuencas costeras de la región de Valparaíso, además de su impacto en la conservación y protección de su cortejo florístico.

\section{Área de estudio}

La región mediterránea en Chile se extiende aproximadamente entre los $32^{\circ}$ y $36^{\circ}$ de latitud sur. En su extremo septentrional $\left(32^{\circ}-33^{\circ}\right.$ latitud sur) se localiza la región política administrativa de Valparaíso, lugar donde está distribuida precisamente el área de estudio, correspondiente a las microcuencas o quebradas costeras de las ciudades de Valparaíso y Viña del Mar. Entre estas microcuencas periurbanas se encuentran: El Quiteño, Las Siete Hermanas, Alto Tranque, Rodelillo, Cabriteria y Santos Ossa (fig. 1). 


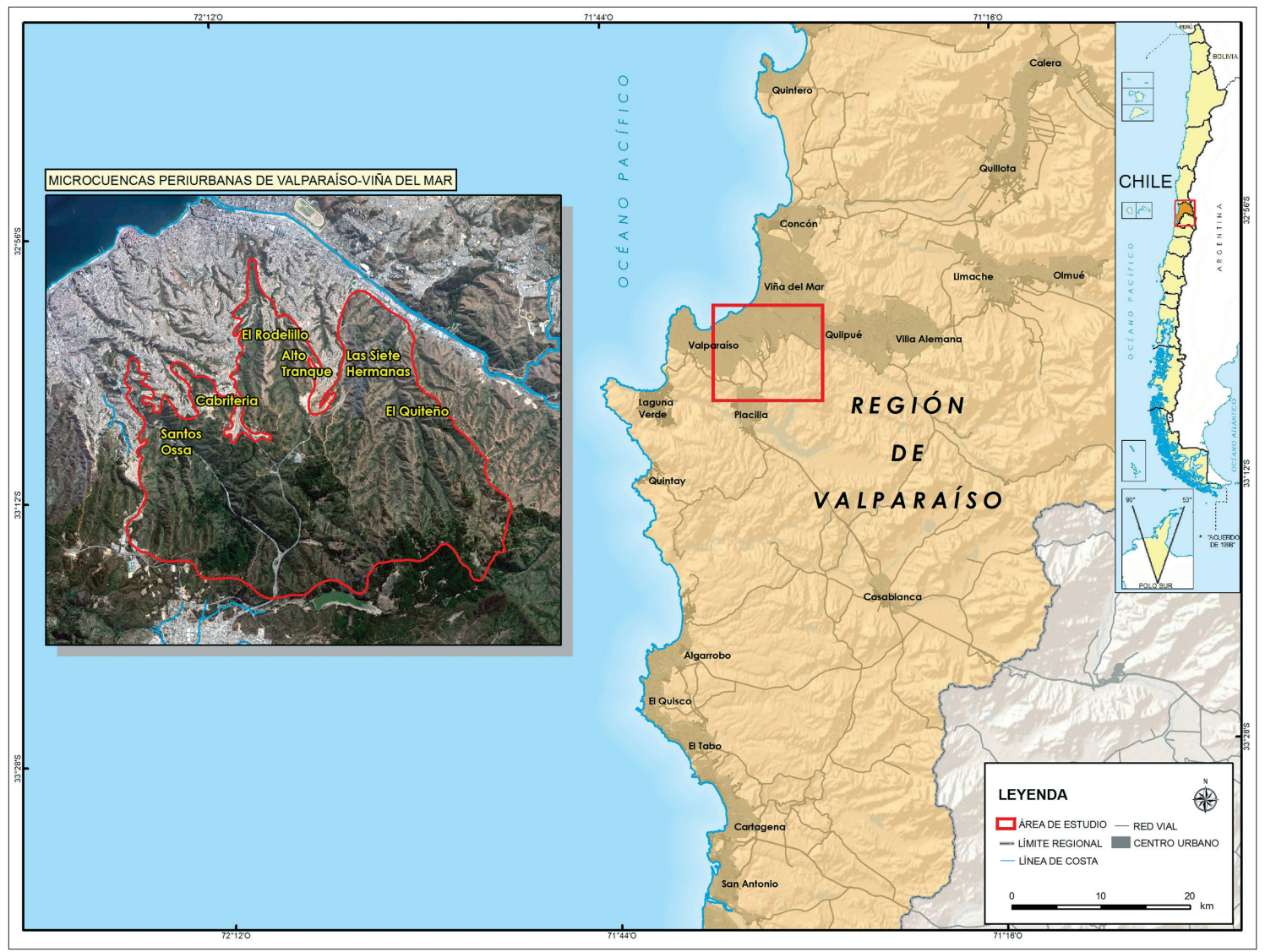

Fig. 1 - Microcuencas periurbanas de las ciudades de Valparaíso y Viña del Mar. Región de Valparaíso.

Fig. 1 - Peri-urban microbasins of Valparaiso and Viña del Mar cities. Region of Valparaíso.

Antecedentes de las condiciones mesológicas de las microcuencas costeras

Las microcuencas o quebradas El Quiteño y Las Siete Hermanas, forman parte del Santuario de la naturaleza Palmar de El Salto, ubicado en los $33^{\circ} 03^{\prime} \mathrm{S}$ y $71^{\circ} 32^{\prime} \mathrm{W}$, en la comuna de Viña del Mar. Estas dos microcuencas presentan las mayores concentraciones costeras de palmas chilenas. Se orientan de sur a norte, con altitudes que oscilan entre los 90 y 250 m.s.n.m., siendo de morfología estrecha y de fuertes pendientes.

Con respecto a las características litológicas y de geomorfología del área de estudio, las microcuencas están situadas sobre terrazas de abrasión marina de edad pliocénica, las cuales presentan un relieve de aspecto colinar con lomajes convexos-cóncavos suavemente ondulados, y en parte, disectados por numerosos cursos de agua (quebradas) de orientación general sur-norte, que desembocan en un colector mayor correspondiente al arroyo Marga-Marga o Estero de Viña del Mar. Este curso hídrico posee una amplia variación de caudal estacional debido fundamentalmente al régimen pluviométrico propio del clima mediterráneo, con precipitaciones concentradas sobre todo en otoño e invierno (C. Caviedes, 1992; L. Flores-Toro y F. Aguirre-Saavedra, 2008).
Entre los factores asociados al régimen de incendios, el clima aquí desempeña un rol importante. Las condiciones atmosféricas de la región mediterránea chilena están caracterizadas principalmente por un prolongado, seco y caluroso verano, el cual frecuentemente se encuentra acompañado por vientos que alcanzan gran intensidad, lo cual tiene una gran incidencia en el surgimiento, expansión y duración de los incendios.

En el sector de nuestra área de estudio predomina un clima templado cálido con lluvias invernales y con estación seca de gran nubosidad. Este sector costero se caracteriza por una gran cantidad de nubosidad que se observa todo el año, con mayor intensidad en invierno, asociada a nieblas y lloviznas lo que produce bajas amplitudes térmicas. La diferencia de temperatura media entre el mes más cálido y el mes más frío es de solo $5^{\circ}$ a $6^{\circ} \mathrm{C}$ y la diferencia entre las temperaturas máximas y las mínimas diarias varía entre $7^{\circ} \mathrm{C}$ en verano y sólo $5^{\circ} \mathrm{C}$ en invierno, lo que es entre $1^{\circ} \mathrm{Y} 2^{\circ}$ inferior respectivamente comparado con la región semiárida situada unos 200 kms. más al norte. La humedad atmosférica es alta, con un valor medio de 82\% (Moreira (2011).

Las corrientes atmosféricas provenientes del suroeste llegan en verano al litoral, regularmente con una alta 
velocidad (sobre los $40 \mathrm{~km} / \mathrm{hr}$ ) favoreciendo la ignición de la vegetación. También contribuyen a los períodos de estrés hídricos en las plantas, con abundancia de días cálidos y secos durante el verano, en tanto que la evaporación puede alcanzar a los $453 \mathrm{~mm}$ en Enero y un mínimo en Junio de $191 \mathrm{~mm}$. La temperatura máxima media en este mes más cálido alcanza los $22,4^{\circ} \mathrm{C}$, en tanto que la pluviometría anual es de $389 \mathrm{~mm}$, presentando una humedad atmosférica alta, con un valor medio de $82 \%$ (R. Novoa y S. Villaseca, 1989; Moreira, 2011).

En la fig. 2 se puede observar que las precipitaciones se concentran en la estación de invierno (Junio-JulioAgosto), mientras que las máximas temperaturas se presentan en la temporada de verano (Diciembre, Enero y Febrero). La estación seca comienza en noviembre y termina en abril, de manera que se prolonga por casi 7 meses, que corresponde a su vez al período de alerta de incendios en Chile.

Con respecto a la caracterización de los suelos, y de acuerdo a lo señalado por W. Luzio (2010), en estos microrelieves costeros se destaca la formación de horizontes diagnósticos subsuperficiales y epidonesmólicos. Predominan las pendientes entre 15 a $20 \%$, sin embargo, en los sectores de lomajes y colinas son frecuentes las pendientes de más de $30 \%$. La profundidad de la parte superficial del suelo y el conjunto de horizontes (el solum) generalmente es mayor a un metro, y sólo en algunos casos es ligeramente profundo (menos de $50 \mathrm{~cm}$ ). La clase textural del horizonte superficial

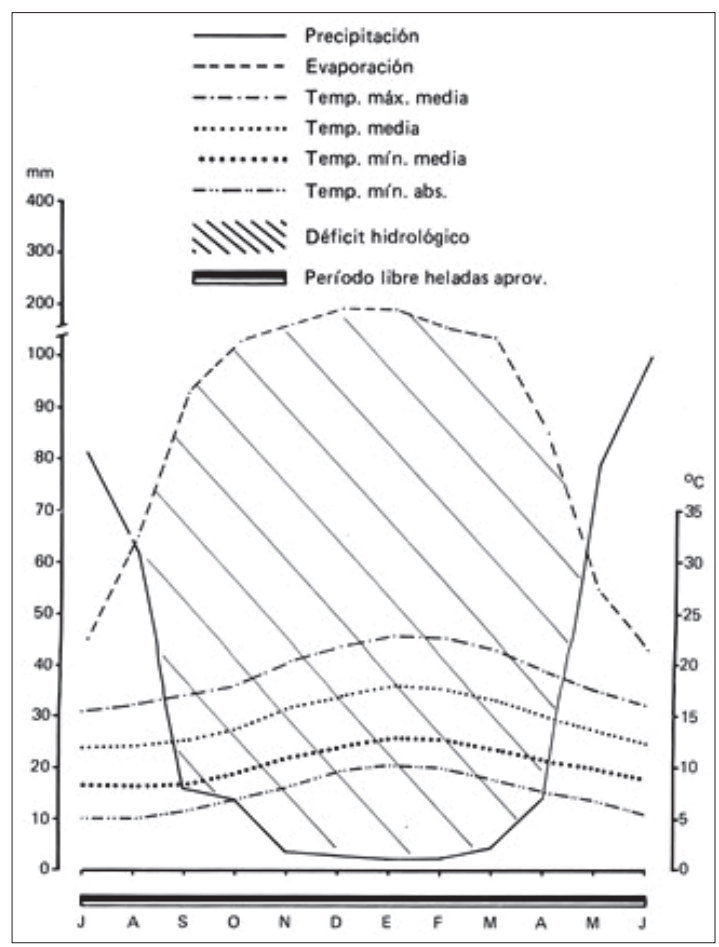

Fig. 2 - Climodiagrama de Valparaíso (Novoa-Villaseca, 1989).

Fig. 2 - Climate diagram of Valparaiso (Novoa-Villaseca, 1989). varía desde franca a franco-arcillosa, mientras que en los horizontes más profundos varía desde franco-arcillolimosa hasta franco-arcilloso. Mientras que el $\mathrm{pH}$ del suelo sería ligeramente básico entre 7,19 a 7,35. Como consecuencia de las fuertes pendientes, la capa orgánica del suelo es muy baja, por lo que está muy expuesta a la erosión (V. Quintanilla y M. Morales, 2012).

\section{Metodología}

Como primer antecedente, se efectuó una revisión bibliográfica de los distintos estudios referidos a los bosques costeros de Chile mediterráneo, y por sobre todo, a las agrupaciones de Jubaea chilensis (C. Villagrán y J. Armesto, 1980; L. González et al., 2001; J. Grau, 2004; L. Flores-Toro y F. Aguirre-Saavedra, 2008; V. Quintanilla y M. Castillo, 2009, Castillo, 2016), analizando diferentes temáticas tanto ecológicas, como biogeográficas y de paisaje.

Con respecto a la degradación de los palmares, se identificaron algunos de los elementos territoriales, ya sean físico-naturales y/o culturales que, en cierto grado, han implicado una importante transformación y retroceso del bosque costero mediterráneo. La estimación de éstos se realizó mediante diversas fuentes y estudios acerca de las perturbaciones y degradación de los ecosistemas costeros en la región de Valparaíso, los cuales se han complementado con las investigaciones y trabajos de campo realizados por los autores desde el año 2011 hasta la actualidad, donde se han evaluado tanto los fenómenos de erosión, regeneración postfuego, como también el retroceso y degradación de las formaciones vegetales por la acción antrópica. Para la identificación de las agrupaciones vegetales y reconocimiento de su estado actual, se realizaron algunos muestreos fitosociológicos en las microcuencas o quebradas de El Quiteño y Las Siete Hermanas, además de transectas y perfiles fitogeográficos siguiendo el método de A.H. Gentry (1988) y Camara et al. (2013), el cual basicamente consiste en trazar una línea de 50 metros lo más recta posible, considerando únicamente las fanerófitas, cuyo DAP sea superior a 25 $\mathrm{cm}$, que estén localizadas dentro de una franja de 1 metro definida a cada lado de la línea. Además, se considera la estructura vertical de las especies y se analiza en el campo parcelas con una superficie de no menos 0,6 has. $y$ en el área de estudio se trabajó en 6 parcelas.

Con respecto a los incendios forestales, su análisis se basó en los registros proporcionados por la Corporación Nacional Forestal de Chile (CONAF), los cuales comprenden 19 años de temporadas consecutivas de incendios (periodo 1997-2015). Con estos datos, y mediante la aplicación de un modelo de datos raster, se elaboró una cartografía con las concentraciones históricas de los fuegos, estimando la frecuencia acumulada de incendios por unidad de superficie, definida en 25 hectáreas. 
En tanto el análisis de la erosión de suelos se efectuó a partir del estudio realizado por el Centro de Información de Recursos Naturales (CIREN, 2010), donde se estimaron las áreas con erosión potencial y actual en la región de Valparaíso, a una escala de 1:50.000. La erosión potencial o fragilidad de los suelos se establece según las características topoclimáticas, biológicas e intrínsecas del suelo, que están relacionadas en dos componentes principales: erodabilidad y erosividad. En tanto la erosión actual se define según la erosión potencial y la desprotección vegetacional del suelo, que indicarían a su vez la potencialidad de los suelos de ser erosionados si las condiciones actuales de vegetación se mantienen. Este estudio además se complementó con las observaciones y muestreos realizados en los distintos trabajos de campo por los autores.

También se consideraron las diferentes entidades urbanas presentes en el área de estudio, definidas tanto por el Instituto Nacional de Estadísticas (INE, 2005), como por CIREN (2010) a través de la delimitación del uso de suelo de las áreas urbanas, a modo de poder caracterizar la influencia que poseen los centros poblados sobre las áreas naturales.

\section{Discusión}

El factor antrópico sin duda ha desempeñado en las microcuencas un rol muy importante y perjudicial. En los últimos 20 años se han realizado en el área de estudio una serie de obras civiles de gran envergadura, que han alterado intensamente el paisaje natural. Por ejemplo, entre los años 1994 y 1997 se levantó una autopista que atraviesa las colinas y quebradas del sector, mientras que en el año 1999 se construyó la tubería de un gasoducto que cruza las laderas del palmar, cuya finalidad es abastecer de gas a la ciudad de Viña del Mar (fot. 1). Posteriormente se instalaron torres de alta tensión eléctrica y de celulares en los sectores más elevados de estas microcuencas, por lo que se habilitaron caminos para facilitar el acceso de

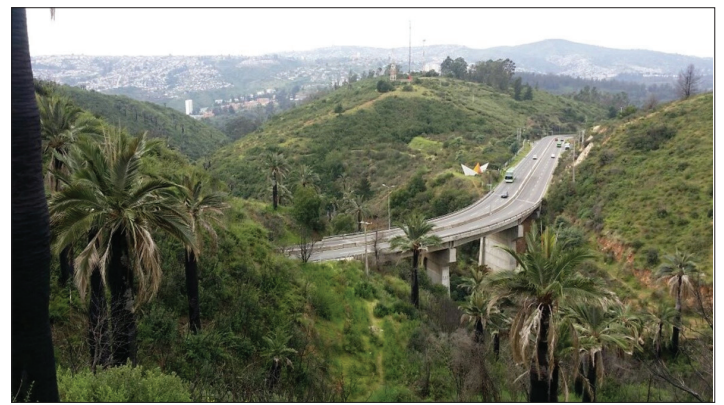

Fot. 1 - Autopista que atraviesa las colinas litorales de la ciudad de Viña del Mar.

Photo 1 - Highway that crosses the coastal hills of the city of Viña del Mar. maquinarias y camiones, implicando que se abriera una verdadera red caminera que destruyó enormemente la cubierta vegetal, incluyendo la destrucción de un centenar de palmas chilenas, alterando la composición florística y dando paso a la erosión (L. Flores-Toro y $\mathrm{F}$. Aguirre-Saavedra, 2008).

Por otra parte, el sostenido aumento de la población en las ciudades de Valparaíso y de Viña del Mar, hoy día conurbadas, generó una expansión urbana de asentamientos espontáneos e irregulares hacia este sector de colinas con matorral esclerófilo y palmeras, que ha ido generando fuertes impactos en el medio. Estos habitantes, que han ido colonizando de forma caótica e incontrolada estas laderas, han sido los responsables de varios incendios, dedicándose además a recolectar las semillas o coquitos de las palmas para comercializarlas para repostería y otros requerimientos.

Otro factor biótico que se debe destacar es la acción del ganado de vacunos y equinos, que como aquí se desplazan de manera dispersa, frenan con frecuencia la recuperación de la vegetación postfuego, sobre todo de hierbas y arbustos. Su contribución a activar procesos erosivos es también bastante alta.

También debe mencionarse el rol de herbívoros silvestres, que no son escasos en las microcuencas. Muy en particular es el ejemplo de un roedor nativo el "degú" (Octodon degus), un pequeño mamífero muy común en los bosques de palmas chilenas, el cual reduce la regeneración de la palma al comerse gran parte del fruto de ella (F. Aguirre et al. 2011).

\section{Las estadísticas sobre Jubaea chilensis}

En la actualidad no existen mayores registros de censos de la palma chilena a nivel nacional ni sectorial, sólo aproximaciones o estimaciones de organizaciones privadas, o de la Corporación Nacional Forestal (CONAF) y de algunos investigadores.

Entre algunos antecedentes históricos y estimaciones realizadas sobre Jubaea chilensis, J. Grau (2004) señala que en el área más septentrional de su distribución (31 $\left.{ }^{\circ} 15^{\prime} \mathrm{S}-71^{\circ} 35^{\prime} \mathrm{W}\right)$, entre las cuencas de los ríos Limarí y Quilimarí, y también en las cercanías de las localidades de Chincolco y Petorca, se censaron más de 500.000 palmas a comienzos del siglo XIX. Sin embargo, para el año 1877 existen referencias de la explotación de más de 1.000 individuos en un solo año en la región de Valparaíso, como consecuencia de la explotación de savia para miel.

De acuerdo con estimaciones efectuadas por L. González et al. (2009), en Chile existirían al año 2008, alrededor de 120.000 individuos, considerando 12 sectores de hábitat de la palma en Chile mediterráneo, incluyendo alguna 
de las microcuencas en este estudio (Siete Hermanas, el Quiteño, El Rodelillo). Según J. Grau (2004) a fines de 1950 existían en estas quebradas boscosas, unas 60.000 palmas; mientras que la Corporación de la Flora y Fauna de la Región de Valparaíso (CODEF), contabilizaban en el año 2012 no más de 6.500 palmas maduras.

Los registros más precisos, considerando diversas variables, son hasta ahora los realizados por González et al. (2001). Este estudio poblacional se efectúo en una superficie de colinas costeras de 1.778 hectáreas, casi circundantes a poblaciones urbanas que hoy están muy próximas de los palmares. Apoyándose en fotointerpretación, trabajo de campo, y en criterios de la estructura de la población, definieron subunidades de 10 hectáreas cada una, en la cual efectuaron inventarios, considerando el número de individuos, la altura, el estado de desarrollo y el estado sanitario de la especie. La vegetación acompañante se censó por estratos, estableciendo finalmente tablas de frecuencia y gráficos de altura. En la TABLA I y fig. 3 se resume los principales resultados de este estudio censal de palmas:

TABLA I. Superficie y densidad de palmas.

TABLE I. Surface and density of palms.

\begin{tabular}{|l|l|l|}
\hline Densidad & Palmas por hectárea & \multicolumn{1}{|c|}{$\begin{array}{c}\text { Superficie según } \\
\text { Densidad }\end{array}$} \\
\hline Baja & 1 a 5 palmas & $1,212,6$ ha \\
\hline Media & 6 a 10 palmas & 81,6 ha \\
\hline Alta & Sobre 10 palmas & 179,9 ha \\
\hline \multicolumn{2}{|c|}{ Total superficie con palma chilena } & 1.474 ha \\
\hline
\end{tabular}

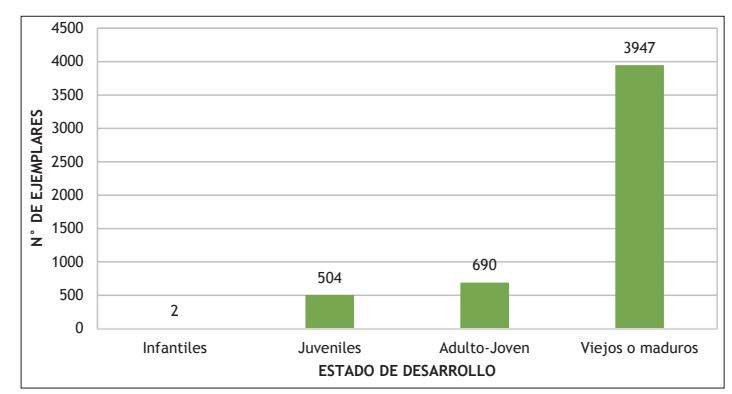

Fig. 3 - Estructura de la población de palma chilena (González et al., 2001).

Fig. 3 - Structure of the Chilean palm population (González et al., 2001).

A la fecha, casi 10 años posteriores a estos inventarios, se comprueba mediante la observación de imágenes de satélites Landsat 2015-2016 y recorridos de campo, que la cantidad de palmas ha disminuido aproximadamente alrededor de un 10\%, y no exclusivamente a causa de los incendios, sino más también por la erosión y la apertura de senderos y huellas realizados para introducir ganado dado que la mayoría de estos terrenos de las microcuencas pertenecen a propietarios privados.

\section{Estructura florística del matorral esclerófilo asociado a Jubaea chilensis}

En estas microcuencas se realizaron censos y transectas lineales para conocer la composición del sotobosque, en áreas que han sufrido numerosos incendios estivales a la fecha, complementado con en el análisis del estudio de L. Flores-Toro y F. Aguirre-Saavedra (2008). La flora vascular se compone de siete elementos identificados, al menos, al nivel de género: Calandrinia, Ranunculus, Schizanthus, Viola, Alstroemeria, Crepis y Juncus. Encontraron 234 especies, el 75,64\% son autóctonas (nativas y endémicas) y sólo el $24,36 \%$ corresponde a especies introducidas (fig. 4). Aquí se encuentra casi el $10 \%$ de toda la flora de la región mediterránea de Chile central, la que por lo demás, y según Arroyo et al., 1995, alberga un total de 2.400 especies de plantas vasculares.

En inventarios realizados en las microcuencas de El Quiteño se encontró que era relativamente constante la presencia en el estrato arbóreo, de casi la totalidad de los elementos leñosos representativos del bosque esclerófilo mediterráneo de Chile, inclusive aquellos de hábitat húmedos (Quillaja saponaria, Litrahea caustica, Peumus boldus, Cryptocaria alba, Kageneckia oblonga,Maytenus boaria, Podanthus mitiqui).

Por otra parte, existen endemismos notables como el arbusto Adesmia balsámica Bertero ex Hook et Arn. que es una especie endémica de la región de Valparaíso, hoy en día en peligro de extinción (L. Flores-Toro y F. Aguirre-Saavedra, 2008). También es importante

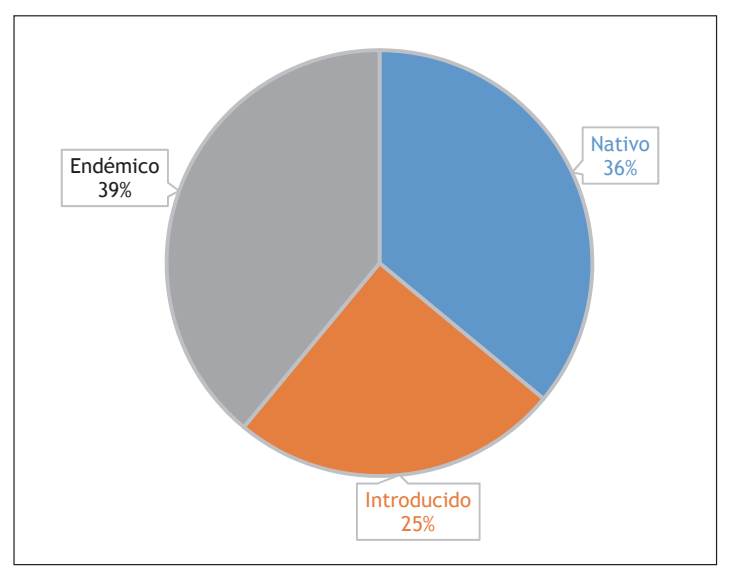

Fig. 4 - Origen fitogeográfico de la flora del Santuario de la Naturaleza Palmar El Salto, El Quiteño y 7 Hermanas.

(L. Flores y F. Aguirre, 2008).

Fig. 4 - Phytogeographic origin of the flora of Santuario de la Naturaleza Palmar El Salto, El Quiteño y Siete Hermanas (L. Flores and F. Aguirre, 2008). 
destacar la presencia de dos especies endémicas de la región mediterránea, cuyo límite norte es precisamente la región de Valparaíso, siento estas: Myrceugenia lanceolata (Juss.ex J.St.-Hil) Kausel, preferentemente en el fondo de las microcuencas y Adesmia loudonia Hook .et Arn que prefiere la parte alta de las microcuencas.

También Flores et al. (2008), citan aquí muchas herbáceas típicas mediterráneas. En cuanto a las formas de vida, las más abundantes son las fanerófitas $(38,46 \%)$ seguidas de las hemicriptofitas con 57 especies Como en todo Chile mediterràneo, las plantas introducidas son bastante numerosas. Así en 25 familias están predominando las Asteraceae y Poaceae aunque no siempre con una cobertura importante. Entre las introducidas más frecuentes destacan: Rubus ulmifolius y Teline monspessulana, en tanto que entre las denominadas malezas debe señalarse como constantes a Euphorbia peplus y Fumaria capreolata. Teline monpessulana, posee hoy día un gran poder de regeneración en ambas laderas de las microcuencas favorecido por los fuegos.

En estado de amenazadas existirían 9 especies y las menos constantes son inclusive Myrceugenia rufa y Adesmia balsámica. Como vulnerables es dable consideran hoy día a Jubaea chilensis Mol. (Baillon), a Blepharocalyx cruckschanksii ((Hook er Arn). Por otra parte, la presencia de herbáceas endémicas en el área de estudio sería relevante lo que contribuye a que estas quebradas apoyen también la percepción que se tiene y que corresponde a la parte central de Chile, de considerarlas como una de las 34 regiones prioritarias para la conservación de la biodiversidad a escala mundial (Myers et al., 2000, Mittermeir et al., 2005, en Flores et al., 2008).

En cuanto a especies amenazadas existirían 9 y la mayoría está en categoría de conservación vulnerable, particularmente Myrceugenia rufa (Colla) y Adesmia balsámica.

Ahora respecto al rol del fuego en estas comunidades no deja de ser importante. Precisamente las 4 especies que presentan los valores de mayor importancia en el Santuario, son aquellas que se caracterizan por colonizar áreas que han sido devastadas por los incendios o que poseen alguna cualidad que les permite resistir a este tipo de alteraciones (V. Quintanilla y C. Reyes 1999; R. Villaseñor y F. Saiz 1993). De este modo Nasella chilensis, Chusquea cumingii y Retanilla trinervia son especies autóctonas que actúan como pioneras al brotar tras un incendio.

En el estudio de L. Flores-Toro y F. Aguirre-Saavedra (2008) se destaca que tanto Chusquea cumingii como Retanilla trinervia forman agrupaciones casi puras en diversos sectores de las laderas de las microcuencas, sin distinción de la exposición o de altitud en la que se encuentren, ocupando gran parte del estrato arbustivo del palmar, mientras que Nasella chilensis cubre grandes áreas del estrato herbáceo.
Por otra parte, Jubaea chilensis ha sobrevivido a este régimen de incendios permanentes porque en estado adulto, no se ve afectada por el fuego ( $R$. Villaseñor y F. Saiz 1993).

Antecedentes de los Incendios forestales en las microcuencas

De acuerdo con el análisis de los registros de incendios para el periodo 1997-2015, en la región de Valparaíso se pueden identificar algunas concentraciones de alta densidad de fuegos, que estarían presentes mayormente en las áreas periurbanas de las principales ciudades de la región, entre las cuales se destacan Valparaíso y Viña del Mar, que por lo demás son las urbes más importantes de la región, y de toda la franja litoral de Chile Mediterráneo, en términos de tamaño poblacional y de área urbana funcional (fig. 5).

El área de estudio está emplazada precisamente en estas áreas periurbanas y rurales que rodean Valparaíso y Viña del Mar, lugares de relieve donde se concentra cerca del $18 \%$ de los incendios registrados anualmente en la región, cuyos focos de los fuegos estarían relacionado principalmente a las áreas de conectividad vial y a los sectores dominados por profundas quebradas (Castillo et al., 2009) (fig. 6).

Según los datos obtenidos para el periodo 1997-2015, en las microcuencas en estudio se han registrado en total 688 incendios, de diversa magnitud, destacando solo tres episodios de incendios que han afectado un área por sobre las 200 hectáreas (incendio de magnitud), correspondientes a los años 1997, 2004 y 2012, los cuales coincidirían con los máximos registros de superficie quemada. Sin embargo estos incendios de magnitud no necesariamente estarían relacionadas a las mayores frecuencias de los fuegos, con excepción de la temporada 1997, que si bien ocurrió un siniestro de magnitud, el tamaño medio de los incendios para aquel año fue más regular, al igual que la temporada 2014 (fig. 7).

La ocurrencia de los incendios en las microcuencas en los últimos 19 años ha sido en promedio de 36 incendios anuales, afectando una superficie estimada de 157 hectáreas al año, de las cuales en un 70\% correspondería a vegetación nativa en sus distintos estratos fisionómicos, incluyendo las agrupaciones de palma; y el $30 \%$ restante representaría principalmente a las plantaciones de Pino y Eucaliptus, cuya presencia en la región no es menor (fig. 8). De acuerdo a ello, cabe señalar en un contexto histórico, que, a comienzos de la década de 1960 , en los sectores ribereños del Lago Peñuelas (sureste de la ciudad de Valparaíso), se iniciaron las plantaciones arbóreas exóticas de Pinus radiata y Eucalyptus globulus. 
RISCOS - Associação Portuguesa de Riscos, Prevenção e Segurança

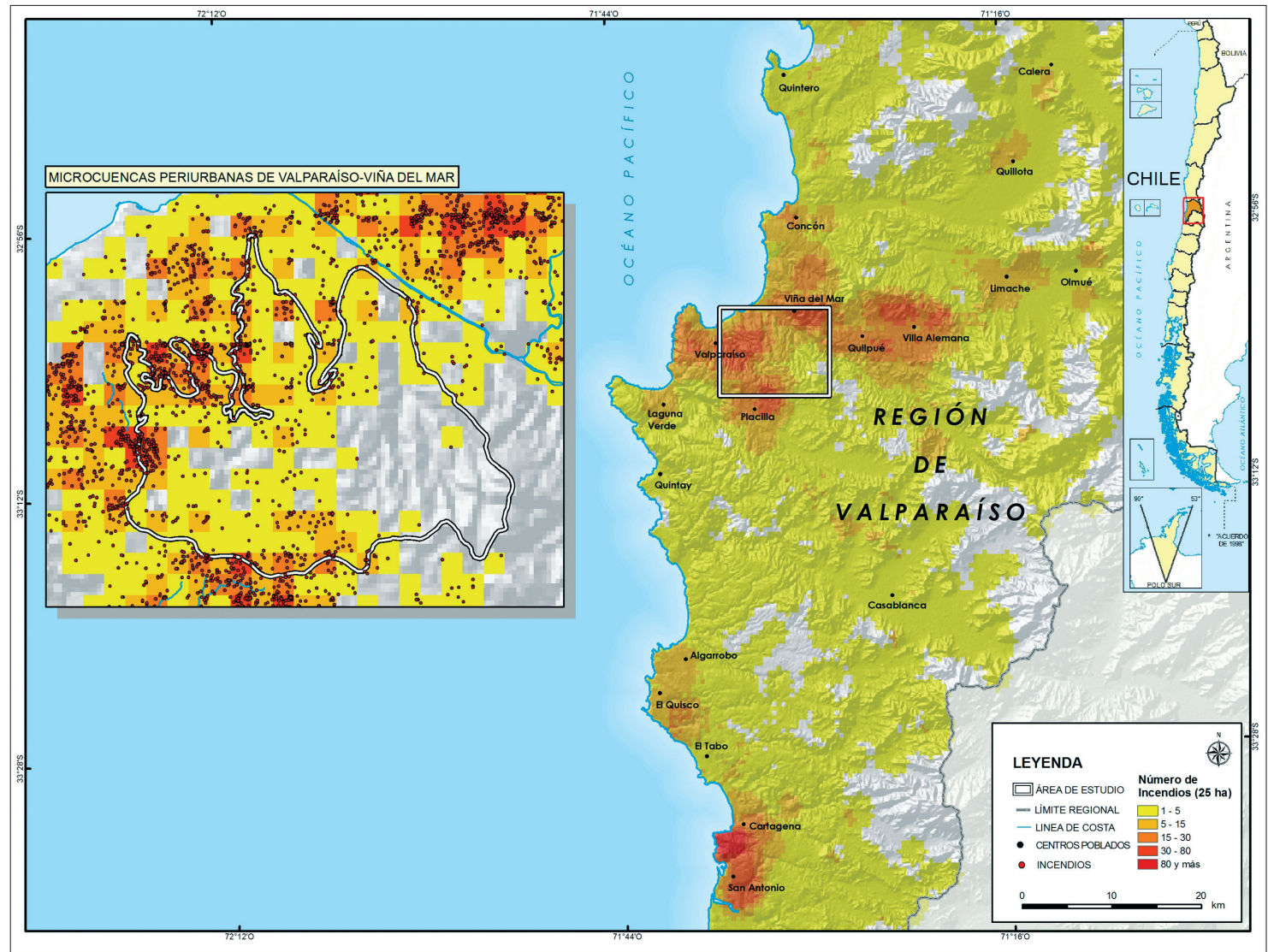

Fig. 5 - Áreas críticas de ocurrencia de incendios en la región de Valparaíso (1997-2015).

Fig. 5 - Critical areas of occurrence of fires in the Valparaiso region (1997-2015).

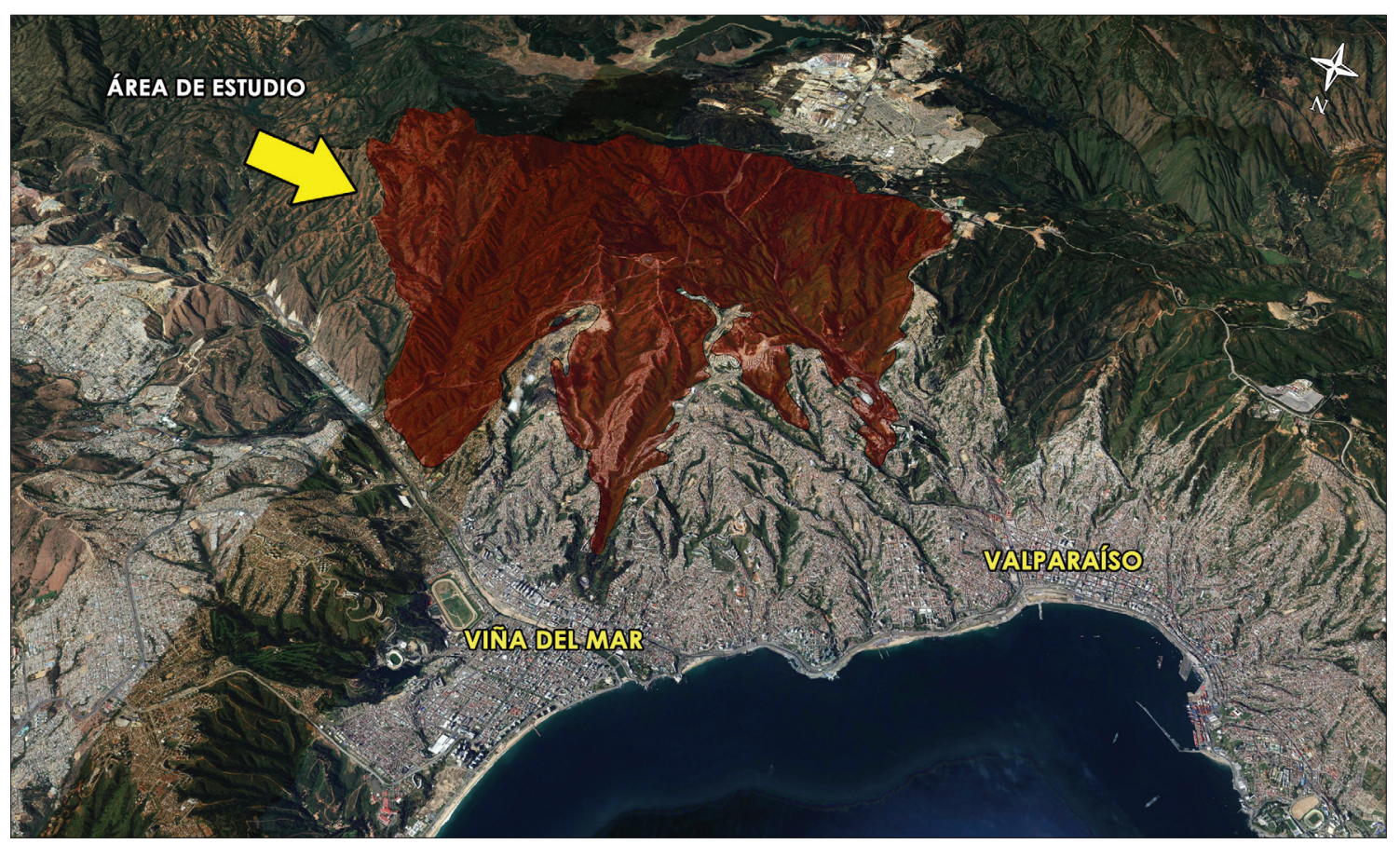

Fig. 6 - Áreas periurbanas y rurales de las ciudades de Valparaíso y Viña del Mar.

Fig. 6 - Peri-urban and rural areas in the cities of Valparaíso and Viña del Mar. 
Estos bosques prácticamente ahogaron a las palmas chilenas que estaban próximas a esos sectores, convirtiéndose en elementos vegetales con alto riesgo de combustibilidad; $y$, en consecuencia, numerosos incendios estivales se han expandido hacia las microcuencas de El Salto y El Quiteño, afectando importantes agrupaciones de palmas chilenas (fot. 2).
De acuerdo a la distribución espacial y densidad de los fuegos en las microcuencas, se debe mencionar que las mayores concentraciones y frecuencia acumulada de los incendios por unidad de superficie, han estado vinculadas fundamentalmente a los sectores de mayor accesibilidad, que están bajo la presencia de algún eje vial, ya sea carretera, camino secundario, sendero, etc.,

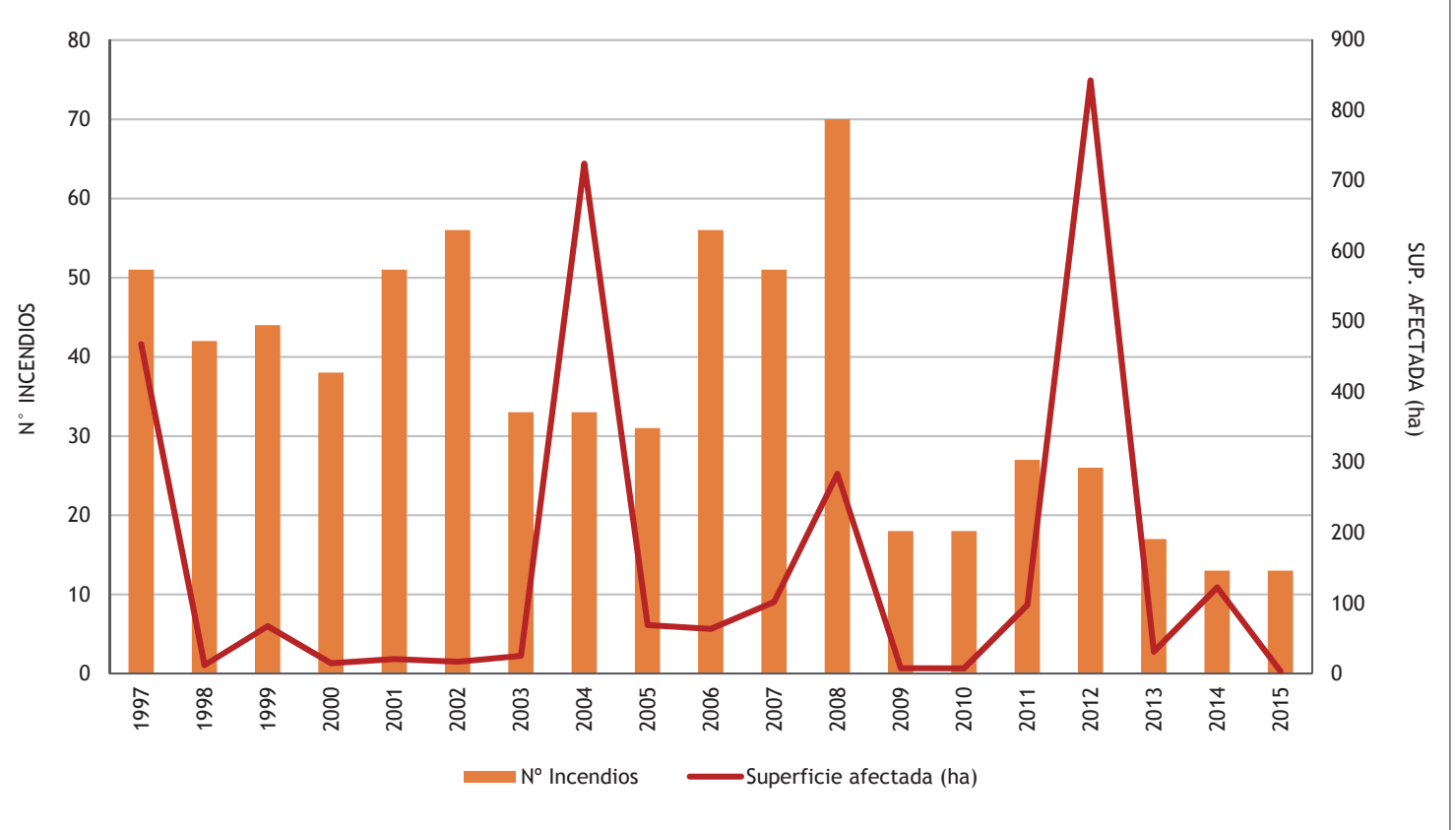

Fig. 7 - Ocurrencia histórica de los fuegos y superficie afectada (ha) en el periodo 1997-2015.

Fig. 7 - Historical occurrence of fires and affected area (ha) in the period 1997-2015.

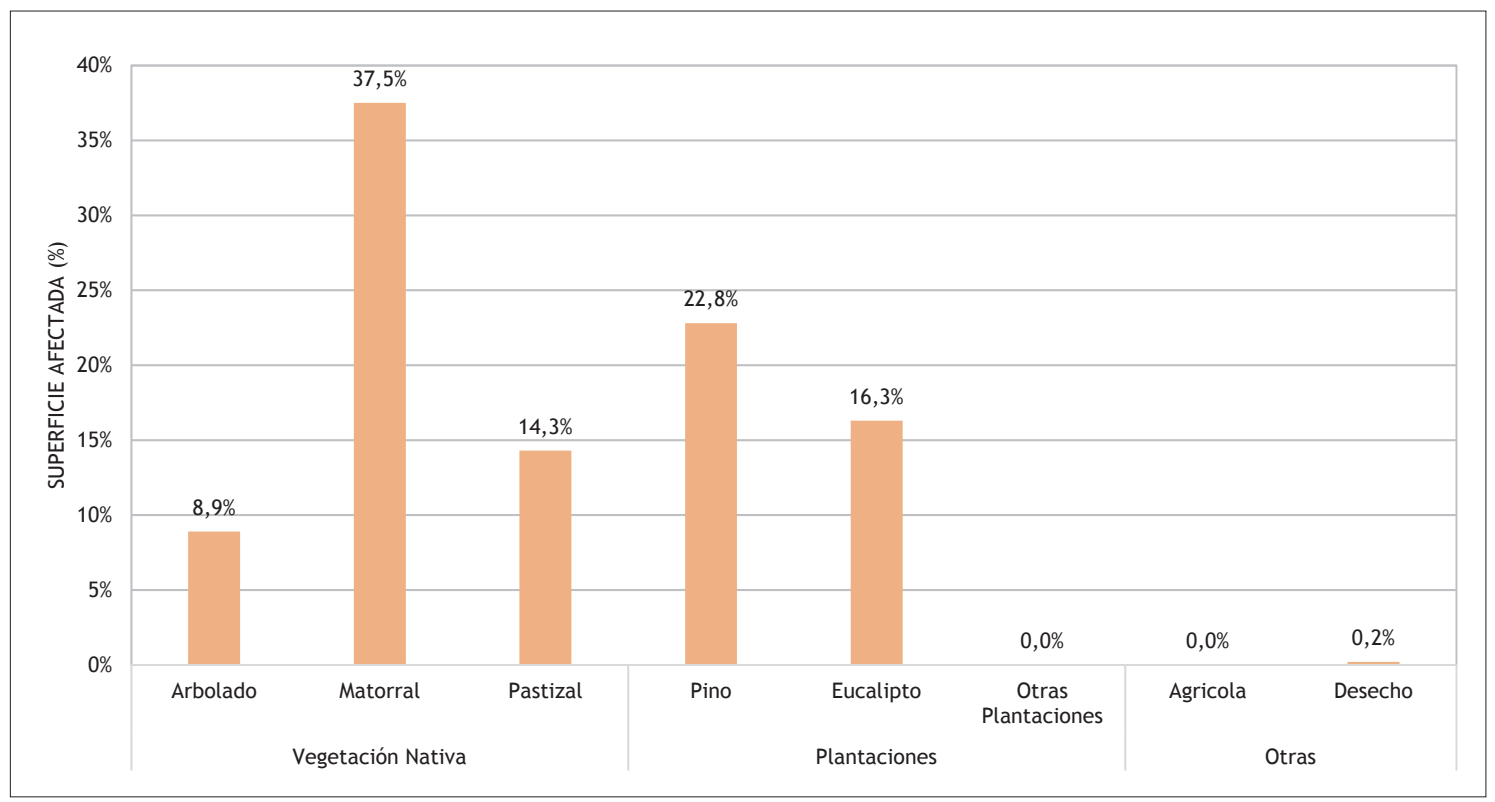

Fig. 8 - Tipo de superficie dañada por los incendios (\%) en el periodo 1997-2015.

Fig. 8 - Type of area affected by fires (\%) in the period 1997-2015. 




Fot. 2 - Microcuenca El Quiteño afectada por un incendio del 14 de febrero del año 2015.

Photo 2 - El Quiteño microbasin affected by a fire on February 14, 2015.

siendo estos lugares los principales focos de incendios, que representan cerca del $70 \%$ del total de los fuegos registrados en al área.

Entre los sectores que presentarían una mayor densidad y ocurrencia de fuegos, se destacan las microcuencas de Santos Ossa, Cabriteria y El Rodelillo, donde se han llegado a producir entre $30 \mathrm{y}$ 80 incendios por cada 25 hectáreas. En tanto en los sectores de Alto Tranque, Las Siete Hermanas y El Quiteño, predominantemente la frecuencia acumulada de incendios ha sido menor, no sobrepasando los 15 incendios por cada 25 ha, por lo que se asume que las agrupaciones de palmas de estas microcuencas han tenido condiciones un tanto más favorables para la regeneración postfuego. No obstante, la dinámica de regeneración postfuego para los distintos sectores del área de estudio, pueden tener ciertas diferencias que están supeditadas a diversos factores como la magnitud y extensión de cada uno de los incendios; las condiciones ambientales (relieve, orientación, humedad); elementos florísticos que constituyen el paisaje vegetal, como así también la exposición a otros factores de degradación, ya sea la erosión y/o la influencia urbana o de actividades antrópicas.

El fuego ha implicado el retroceso, y en parte, la modificación del cortejo florístico asociado a estas palmas, exponiendo los suelos a los fenómenos de erosión, particularmente durante la época de lluvias (Quintanilla y Reyes, 1999; Quintanilla y Castillo, 2009). En la medida que se reduzca y se degrade el bosque esclerófilo, el cual ha proporcionado un hábitat adecuado y protector a la palma chilena, quedará más vulnerable en su conservación y recuperación.

Por otra parte, existen varias especies introducidas que adquieren el carácter de invasoras al desarrollarse después de los incendios, siendo evidente por ejemplo la presencia de un cardo invasor (Cirsium vulgare) en laderas de solana, mientras que en los fondos de quebradas la bambúsea Chusquea cumingii ha experimentado una gran expansión. En tanto Retanilla trinervia (Gilles et Hook. (Hook), arbusto nativo, ha tenido un avance bastante notorio en la actualidad, inclusive en sectores de sotobosque, al igual que la gramínea nativa Nasella chilensis (Trin.) E. Desv.

\section{Erosión de suelos}

En el área de estudio se han detectado distintos fenómenos de erosión que han influido, de algún modo, en el estado actual de la vegetación, generando ciertas condiciones de fragilidad para los ecosistemas nativos. Entre los factores que directa e indirectamente han incidido en los procesos de erosión de las microcuencas, y de toda la franja litoral mediterránea, se destacan fundamentalmente: las condiciones climáticas; relieve o topografía; naturaleza y propiedades del suelo, herbivoría y principalmente el factor antrópico.

El clima mediterráneo, dominante en esta región, está caracterizado por grandes contrastes en la distribución anual de las precipitaciones, generando condiciones necesarias para favorecer la acción de las lluvias en los procesos erosivos. Durante los meses de verano la vegetación comienza a disminuir, dejando el terreno con cierta exposición frente a las primeras lluvias invernales, que suelen ser concentradas y torrenciales, produciendo la remoción de la capa superficial del suelo (erosión laminar) y posteriormente, la disección del terreno (Castro y Vicuña, 1990).

De acuerdo a los índices de intensidad y grado de concentración estacional de las lluvias, se hace evidente la agresividad como agente erosivo que adquieren las lluvias en gran parte de la costa mediterránea. Esta situación se puede observar en los sectores de mayores pendientes de las microcuencas, donde los procesos erosivos por agentes hídricos han ocasionado diversos grados de erosión, ya sea de tipo laminar o de erosión en surcos y cárcavas (fot. 3).

Por lo tanto, la topografía también ha tenido gran incidencia en la erosión, donde las microcuencas de estudio presentan por lo general relieves ondulados o con rupturas de pendiente, con valores promedio sobre el $25 \%$, los cuales serían favorables para el desencadenamiento de los procesos de erosión.

De acuerdo a esto se reconoce la importancia del factor topográfico en la potencialidad de erosión, principalmente en aquellos sectores con escasa cobertura de vegetación o de estructura vegetal disminuida (matorral abierto), situadas generalmente en laderas de solana, o en áreas que han sido afectadas constantemente por los fuegos, donde se han alterado diversas agrupaciones de Jubaea chilensis. 


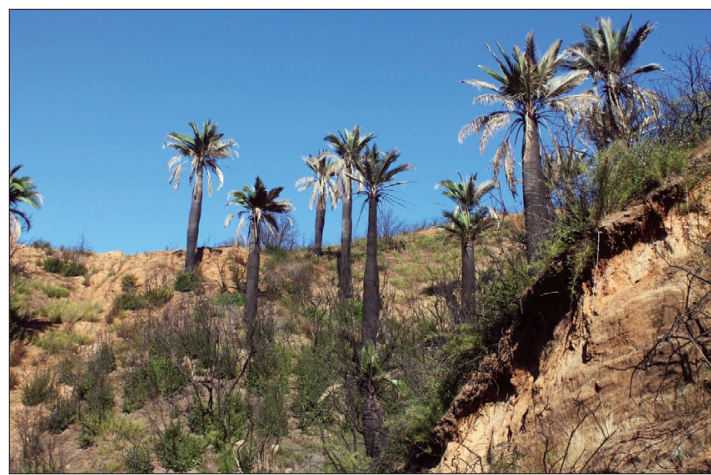

Fot. 3 - Palmas quemadas en fuertes pendientes afectadas por erosión.

Photo 3 - Burned palms and current erosion risk over the micro-basins under study.

La naturaleza y propiedades del suelo también ha sido un factor a considerar en las microcuencas costeras, ya que los suelos están constituidos principalmente por maicillo, producto de la alteración de rocas cristalinas; suelos definidos por CIREN (1997) con clase textural superficial franco arenosa. Si bien estos suelos poseen un buen drenaje, existen varios sectores donde se supera la capacidad de infiltración, teniendo como consecuencia la generación de escorrentía superficial, y en efecto, la generación de procesos erosivos.

Por otra parte, las actividades antrópicas también han incidido en el desencadenamiento de fenómenos de erosión, fundamentalmente por la intervención de las coberturas vegetales nativas a través de los incendios forestales, y en menor medida, por la explotación de bosques (leña, madera) y la acción del ganado (ramoneo y pisoteo).

El estudio de CIREN (2010) consideró precisamente los factores anteriormente señalados para la definición del riesgo de erosión potencial en la región de Valparaíso. De acuerdo a ello, las microcuencas presentarían un rango severo de erosión potencial (sobre el $80 \%$ ), por lo que eventualmente cualquier intervención sobre las coberturas vegetacionales de estas quebradas, implicaría una exposición de los suelos a la erosión (fig. 9).

En tanto la estimación de la erosión actual demuestra en su generalidad que las microcuencas no se encontrarían en rangos críticos de erosión, sino más bien en un nivel ligero y moderado, éste último caracterizado por presentar suelos con pavimentos de erosión en al menos

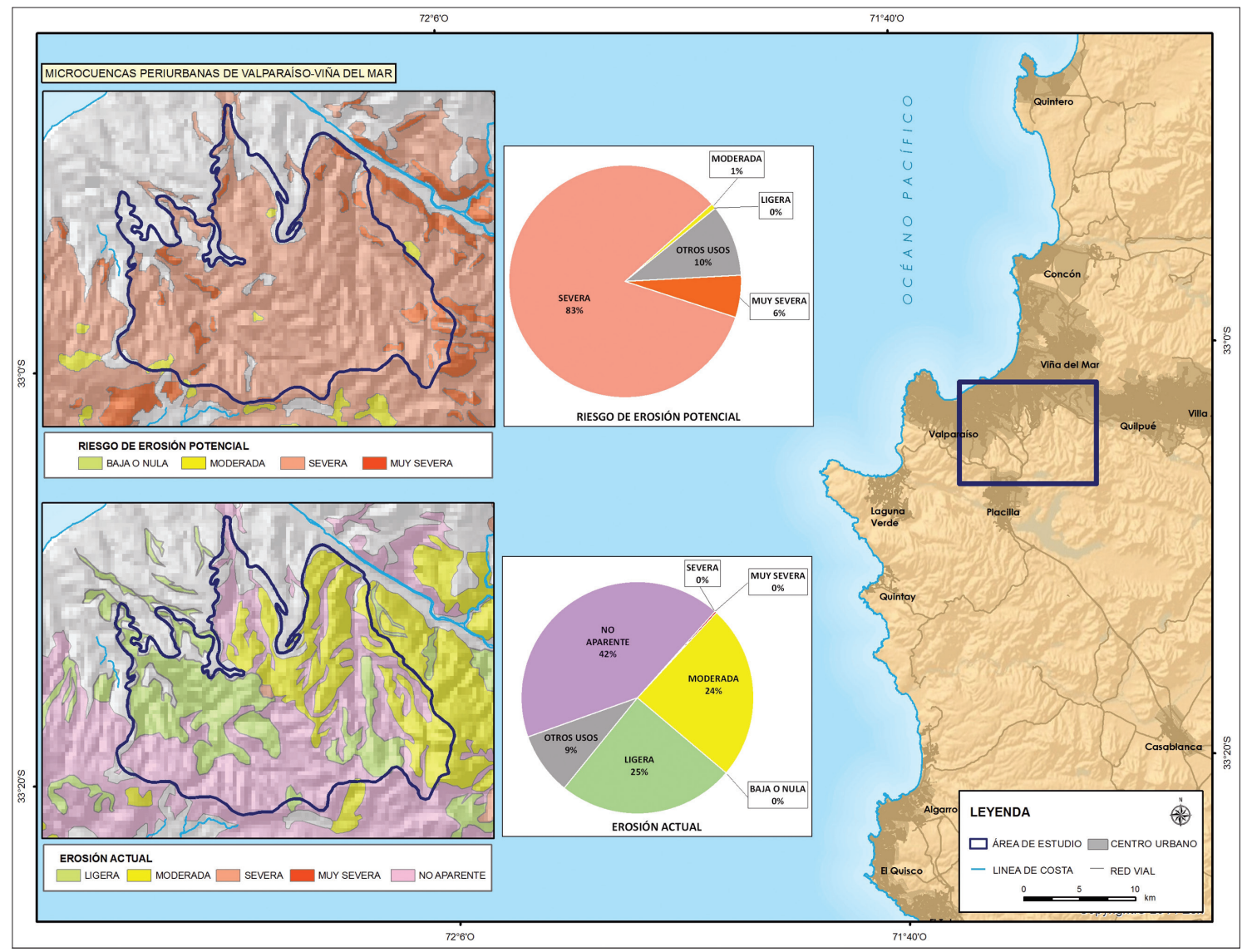

Fig. 9 - Riesgo de erosión potencial y erosión actual en las microcuencas en estudio.

Fig. 9 - Risk of potential erosion and actual erosion in the microbasins under study. 
el $30 \%$ de su superficie, existiendo ocasionalmente surcos. Sin embargo, la presencia del nivel de erosión no aparente es de un 42\%, puede dejar entrever la subestimación de algunos valores reales de erosión, sobre todo en algunas áreas más afectadas por los incendios, donde existe un dominio de especies arbustivas que han tenido una mayor capacidad de propagación y regeneración de espacios alterados, como ha sido el caso de Retanilla trinervia, Chusquea cumingii, Rubus ulmifolius y Nasella chilensis.

Influencia de los centros poblados e infraestructura vial

Las principales entidades pobladas de la región de Valparaíso corresponden a las ciudades de Valparaíso y Viña del Mar, las cuales se destacan tanto por su población como su superficie, estando situadas en sus proximidades de las microcuencas en estudio. En el caso de los urbanos de Valparaíso y Viña del Mar, su población se encuentra sobre los 300.000 habitantes. (INE 2006).

La importancia de identificar la proximidad de los distintos centros poblados como también de la red de carreteras y caminos con respecto a los palmares, tiene relación con la alta incidencia que poseen éstos como focos de incendios, que son ocasionados principalmente por la intencionalidad y el tránsito de las personas, por lo que estas áreas de interfaz urbano-rural representarían un alto riesgo de fuegos.

También la expansión de las entidades urbanas hacia los sectores periféricos de las microcuencas ha generado necesariamente intervención y retrocesos en los bosques esclerófilos e higrófitos en las últimas décadas. Por ejemplo, a comienzos del año de 1980 se inicia en las ciudades de Valparaíso y Viña del Mar un importante crecimiento de la población, que significó intensificar la ocupación de laderas y cimas de colinas, y al mismo tiempo la apertura de nuevos caminos, alterando de este modo la vegetación nativa.

La dinámica de expansión de estas ciudades ha conllevado que en las áreas periféricas se esté construyendo prácticamente en cada lugar donde es posible levantar una vivienda, en su mayoría precarias, logrando socavar la tierra y colmatando las quebradas o microcuencas (V. Quintanilla, 1999).

Este crecimiento urbano ha sido por lo demás perjudicial para el desarrollo y conservación de los palmares, y del bosque esclerófilo en general, por un lado influyendo en el riesgo de incendios (transito e intencionalidad) y también por el deterioro ambiental y de salud que involucra la ocupación espontanea sin planificación de las viviendas, que rebasan en muchos casos las colinas, generando toneladas de basura, escombros y tierra de desecho en el fondo de las quebradas, invadiendo los sectores del palmeral y bosques esclerófilo.
Como se ha señalado antes, junto con el daño asociado a la expansión de los centros urbanos, se encuentra además la construcción de infraestructura vial (autopista y carreteras) e instalaciones de servicios públicos (gaseoductos-electricidad-comunicaciones), que han arrasado en diversos sectores de las microcuencas con cientos de hectáreas de vegetación nativa, incluyendo la destrucción de agrupaciones de Jubaea chilensis ( $\mathrm{J}$. Grau, 2004) (fot. 4).

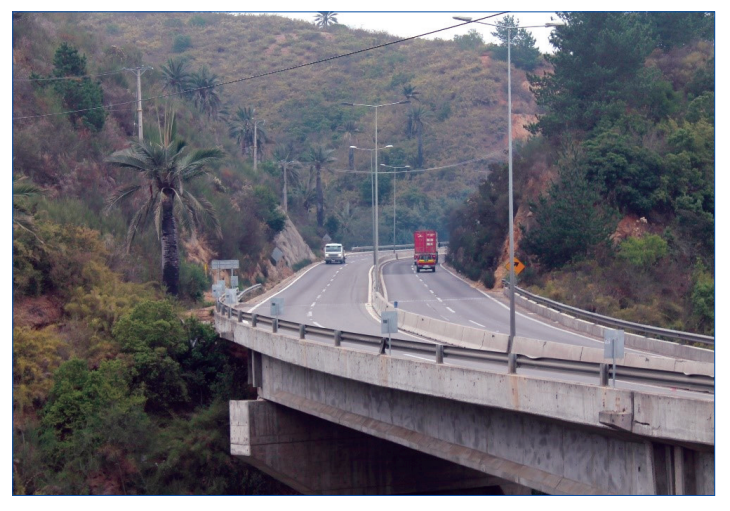

Fot. 4 - Colinas con agrupaciones de palmas disectadas por la construcción de carreteras.

Photo 4 - Hills with palms groups dissected by highway construction.

La fuerte fragmentación que ha experimentado Jubaea chilensis no ha sido únicamente por la expansión y daños directos e indirectos (incendios) de la red vial y de diversa infraestructura, sino también como resultado de 250 años de presión antrópica por sus distintos usos y valor, como la explotación de su savia para elaborar la miel, la colecta de sus "coquitos" o semillas para repostería, y además del uso de sus ramas que tuvieron hasta fines del siglo pasado, una gran utilidad en faenas agrícolas y construcción de "chozas" o modestas casas rurales en las fincas de Chile central. También para ritos religiosos se utilizaron frecuentemente sus ramas u hojas.

\section{Conclusiones}

En la región mediterránea costera de Valparaíso- Viña del Mar se desarrollan poblaciones de la palma chilena (Jubaea chilensis (Mol) Baillon, asociada al bosque esclerófilo del país. Los incendios en estas comunidades se presentan consecutivamente por lo menos desde hace 20 años durante el largo y seco verano, afectando notoriamente al cortejo florístico de la palma.

Así la frecuencia de fuegos ha ido alterando el estrato del sotobosque tanto de la palma como de las comunidades forestales al punto que existe cerca de un $30 \%$ de hierbas y arbustos introducidos que se desarrollan rápidamente a continuación de los incendios. Teline monspessulana, arbusto europeo, con posterioridad 
a los fuegos desarrolla una gran cobertura durante la primavera reemplazando a algunos arbustos nativos. La palma hasta ahora, no obstante, se observa poco dañada por los incendios, pero si la regeneración de individuos infantiles es intensamente afectada por los siniestros.

Además, la expansión de una gran conurbación urbana próxima a las microcuencas o quebradas, ha ido produciendo impactos cada vez más regulares en estos bosques que actúan como refugio de importantes especies endémicas de Chile mediterráneo.

\section{Agradecimientos.}

Se agradece al Proyecto $\mathrm{n}^{\circ}$ 091612QP del DICYT de la Universidad de Santiago de Chile por su apoyo a esta investigación. Igualmente, a las ayudantes de investigación Rebeca Pérez Lavín y Valentina Cárdenas Venegoni.

\section{Bibliografía}

Aguirre, Francisco; Ibañez, Gonzalo; Bogdanic, Susana y Ray, Cristian (2011). Ecological parameters related to the regeneration of chilean palm forest (Jubaea chilensis (Moll) Baillon. The Ruffor smale Grants Foundation. $20 \mathrm{p}$.

Arroyo, Mary Kalin.; Cavieres, Lohengrin; Marticorena, Clodomiro y Muñoz-Schick, Melica (1995). Convergence in the Mediterranean floras in Central Chile and California: Insights from comparative Biogeography. In: Arroyo, M. T.R, P.H. Zedler y M.D. Fox (Eds.) Ecology and Biogeography of Mediterranean Ecosystems in Chile, California and Australia. Springer Verlag, Ecological Studies. 108:43-88.

Benoit, Iván (1989). Libro Rojo de la Flora Terrestre de Chile. Primera parte. CONAF, Chile. 157 p.

Camara Rafael y Díaz del Olmo F. (2013). Muestreo en transectas de formaciones vegetales de fanerofitas y camèfitas (I). Fundamentos metodológicos. Estudios Geogràficos Vol. LXXIV: 67-88

Castillo, Miguel; Julio, Guillermo; Garfias, Roberto y Correa, Luis (2013). Incendios forestales en Chile. Análisis general de riesgos. En: Riscos Naturais, Antrópicos e Mistos. Homenagem ao Professor Doutor Fernando Rebelo. Departamento de Geografía, Faculdade de Letras, Universidad de Coimbra. p. 667-678.

Castillo, Miguel (2016) Instituciones de Chile para la defensa contra incendios de interfaz urbanoforestal. Territorium 23:215-221

Castro, Consuelo y Vicuña, Patricia (1990). Caracterización de la erosión lineal en planicies costeras de Chile Central. Revista de Geografía Norte Grande № 17 : $37-45$.
Caviedes, Cesar (1992). Geomorfología del Cuaternario del Valle del Aconcagua, Chile central. Eds. Friburger Geographische Hefte ${ }^{\circ}$ 11. 153 p.

CIREN - CENTRO DE INFORMACIÓN DE RECURSOS NATURALES (1997). Descripciones de suelos y materiales y símbolos. Estudio agrológico de la V Región. Publicación CIREN N ${ }^{\circ}$ 116. $371 \mathrm{p}$.

CIREN - CENTRO DE INFORMACIÓN DE RECURSOS NATURALES (2010). Determinación de la erosión actual y potencial de los suelos de Chile. Región de Valparaíso. Centro de Información de Recursos Naturales (CIREN). 51 p.

CONAF - CORPORACIÓN NACIONAL FORESTAL DE CHILE (2016), Manual con Medidas para la Prevención de Incendios Forestales. Santiago, 89p.

Donoso, Claudio (1982). Reseña Ecológica de los Bosques Mediterráneos de Chile. Bosque. N 4 (2): 117-142

Echeverría, Cristian; Schiappacasse, Ignacio; Urrutia, Rocío; Cárcamo, Miguel; Becerra, Pablo; Smith-Ramírez, Cecilia y Holmgren, Milena (2010). Restauración de ecosistemas degradados para la conservación de la biodiversidad y el desarrollo rural en la zona semiárida de Chile central. Proyectos REFORLAN - CONICYT RUE 33. Valdivia. Chile. 24 p.

Fernández, Ignacio; Morales, Narkis; Olivares, Luis; Salvatierra, Javier; Gómez, Miguel y Montenegro, Gloria (2010). Restauración ecológica para ecosistemas nativos afectados por incendios forestales. PUC. Santiago de Chile. 161 p.

Flores-Toro, Lorena y Aguirre-Saavedra, Francisco (2008). Riqueza florística del Santuario de la Naturaleza Palmar El Salto, Viña del Mar, Región de Valparaíso, Chile. Gayana, Botánica. V.65 N¹: 33-45.

González, Luis; Toral, Manuel y Garfias, Roberto (2001). Estudio de poblaciones de palma chilena. Avanzado estado de deterioro. Chile Forestal 284: 53-59.

González, Luis; Bustamante, Ramiro; Navarro, Rafael; Herrera, Miguel Ángel y Toral, Manuel (2009). Ecology and management of the chilean Palm (Jubaea chilensis (Mol) Baillon): Current situation and Perspectives. Palms vol. 53 (2)

Gentry, A. H. (1988). Changes in plant comunity diversity and floristic composition on environmental and geographical gradients. Anals of the Missouri Botanical Garden. 75: 1-34

Grau, Juan (2004). Palmeras de Chile. Ediciones Oikos Ltda. 203 p.

INE - INSTITUTO NACIONAL DE ESTADíStICAS (2005). Chile: Ciudades, Pueblos, Aldeas y Caseríos. Instituto Nacional de Estadísticas. Subdirección Técnica. Santiago. Chile. 300 p. 
INE - INSTITUTO NACIONAL DE ESTADísticAs (2006). CHILE: Proyecciones y estimaciones de población Total. País 1950-2050.

Luzio, Walter (2010). Suelos de Chile. Ed. Universitaria, $364 \mathrm{p}$.

Moreira, Andrés. 2011. Geopography plants of Chile. Verlag eds. 320 p.

Novoa, Rafael y Villaseca, Sergio (1984). Mapa agroclimático de Chile, Instituto Investigaciones Agropecuarias, Santiago $221 \mathrm{p}$.

Quintanilla, Víctor y Castro, Roberto (1998). Seguimiento de las cubiertas vegetales postincendios en la zona mediterránea costera de Chile. Serie Geográfica. Vol 7. Universidad de Alcalá Henares. p. 147-154.

Quintanilla, Víctor (1999). Los incendios de vegetación en el cordón costero de Chile Central. El apoyo de la cartografía para su gestión en la prevención y análisis. Caso de estudio. Contribuciones Cient. y Tec.Santiago. $n^{\circ} 120$, p. 1-28.

Quintanilla, Víctor y Reyes, Carla (1999). Modificaciones por efecto del fuego en el bosque esclerófilo de quebradas húmedas de Chile central y su incidencia en la palma chilena. Revista Geográfica Terra Australis n ${ }^{\circ} 44$. I.G.M. p:38- 49.

Quintanilla, Víctor (2002). The influence of fire on forest in temperate Chile. En: Fire Biological Processes. Edited by L. Trabaud and R. Prodon. Backhuys Publishers. p.339-346.
Quintanilla, Víctor y Castillo, Miguel (2009). Degradación de la palma más austral del mundo acelerada por fuegos estivales en cordones litorales de Valparaíso y Viña del Mar ( $\left.32^{\circ} 50^{\prime}-33^{\circ} 02^{\prime} \mathrm{S}\right)$ un caso sostenido de perturbación del paisaje. Investigaciones Geográficas $\mathrm{N}^{\circ}$ 41. p. 41-59.

Quintanilla, Víctor y Morales, Mauricio (2012). Degradación de microcuencas de gran valor geobotánico en la zona costera mediterránea de Chile. Antecedentes para restauración ecológica. Geographicalia, 61, p. 67-69

Redón, Jorge (2003). Flora y vegetación de la cuenca del Estero de Viña del Mar, Quinta Región. Chile. Cuadernos de Investigación $\mathrm{n}^{\circ} 2$ Universidad de Viña del Mar. 60 p.

Sabino, A., Poseiro, P., Rodrigues, A., Reis, M. T., Reis, C. J., Reis, R. and Araújo, J. (2017). Coastal Risk Forecast System, Journal of Geographical Systems (aceite para publicação).

Villagrán, Carolina y Armesto, Juan (1980). Relaciones florísticas entre las comunidades relictuales del Norte Chico y la zona Central con el bosque del Sur de Chile. Boletín Museo Nacional de Historia Natural de Chile. 37: 87-101

Villaseñor, Rodrigo y Saiz, Francisco (1993). Incendios forestales en el Parque Nacional La Campana Sector Ocoa, Va Región, Chile Efectos sobre el estrato arbustivo-arbóreo. Anales Museo Historia Natural de Valparaíso, Chile. 21, p: 15-26 